\title{
The Comparative Research on the Soft Power of Central Capital Cities in Six Provinces of Mid-China
}

\author{
Li Qingquan \\ Hunan University of Science and Engineering \\ Yongzhou, Hunan \\ Liqingquang369@163.com
}

\author{
Zheng Jifeng \\ Hunan Provincial Party School \\ Changsha, Hunan \\ Jfzheng@qq.com
}

\begin{abstract}
The development of Chinese city has entered the competition era of soft power, soft power is an important embodiment of city competitiveness. This paper has carried on a comparative analysis on the soft power of Taiyuan, Zhengzhou, Wuhan, Hefei, Nanchang and Changsha six provincial capital cities in central region from the following eight aspects: cultural attraction, city cohesion, educational development ability, science and technology innovation ability, regional influence ability, image transmission ability.
\end{abstract}

Keywords-Central Region, Provincial Capital Cities, Soft Power, Comparative Analysis

\section{THE RISE OF THE CENTRAL REGION AND THE CONSTRUCTION OF CITY CIRCLE}

The central region is located in the hinterland of China, including Shanxi, Henan, Anhui, Jiangxi, Hubei and Hunan six provinces and linking east, west, north and south, and has very important strategic significance in China's regional development pattern. However, since the reform and opening up, the central region's economic status is declining, and compared with other economic sectors, the relative development level and development speed of central region is apparently lower. To promote central regional economy to develop quickly, in 2004 the Central Government put forward the strategy of "the central region rises abruptly", 《several opinions about promoting the central region to rise abruptly》 was introduced in 2006, which supports the central region to build countrywide grain core main production region, build advanced manufacturing industry base, accelerate the transformation of the old industrial base, the transition of resource city and the reform of state-owned enterprises, solve the weak links of traffic facilities, control ecology and environment and promote the development of education and health undertakings.

Since the implementation of central region rising strategy, the national economy of central region achieved a sustained, steady and rapid growth, the proportion of economic gross occupying countrywide economic gross rises steadily than the strategy was not implemented, fixed assets investment, and social consumption and foreign trade with the society promote the economic growth. With the development of central region rising strategy, central region gradually formed six big city group, which are Shanxi Taiyuan City Circle with Taiyuan as its center, Henan Central City Group with Zhengzhou as its center, Anhui Wanjiang City Belt with Hefei as its center, Poyang Lake
City Group with Nanchang as its center, Hubei Wuhan City Circle with Wuhan as its center, and ChangshaZhuzhou-Xiangtan City Group with Changsha as its center.

\section{THE CONNOTATION AND CONSTITUENT ELEMENTS OF CITY SOFT POWER}

Soft power theory came from Western early strength theory, and the concept of soft power firstly was put forward by Joseph S. Nye in his book --- Soft Power: the Victory Path in World Politics at the end of twentieth Century. He argued that a country's comprehensive national power includes the hard power made up of military, science and technology, economy etc. and also includes the soft power made up of culture, ideology, attraction etc. City soft power is a special force, which reflects the city is in the development and competition, and establishes in the intangible factors like the city culture, government service, the quality of the population, social harmony, and the spread of image, and embodies as cultural attraction, social cohesion, science and technology innovation ability, education development ability, regional influence ability, image transmission ability, etc.

Based on the above contents, combined with the characteristics of international city development, here we think that the city soft power is mainly measured and reflected from the following six aspects: cultural attraction, social cohesion, science and technology innovation ability, educational development ability, regional influence ability and image transmission ability.

\section{A. Cultural Attraction}

Charisma means God's charisma in Greek. It was used by Ernst Troeltsch and adopted by Marx Webb, and refers to a kind of ability, which does not depend on material stimulus or force, but depends on the personality and faith power to lead and inspire. Generally speaking, cultural attraction means a trait owned by the culture especially the sacred, inspiring temperament, which can foresee the future and create miracle, and this kind of temperament has a strong attraction to the people outside this culture and with and gets conscious support of people in this culture.

\section{B. Social Cohesion}

Cohesion means the degree of group members carrying on unity and cooperation to achieve the goal of group activity, the so-called social cohesion refers to the city residents' trust, compliance and obedience to the city, 
reflects as whether city residents are concerned about the development and construction of the city or not, whether non local residents are yearning for the city and settle in this city or not, and city residents stay stability and in order, and harmony between person and person, person and nature, live a happiness life and work in peace.

\section{Educational Development Ability}

Education development ability means a place constituted by research institutes, tertiary institutions, education level etc, which reflects sustainable education development capacity of a place's education development level. Education development ability is a important component of a city's comprehensive strength, and it is closely related to the city's innovation ability, science and technology development level, city's sustainable development.

\section{Science and Technology Innovation Ability}

Science and technology innovation is the general name of technical innovation and original scientific research, and it refers to the process of creating and applying new knowledge and new craft, new technology, using new production method and management mode, developing new product, and providing new service. Science and technology innovation ability refers to the ability of developing, using, promoting new technologies and new management way.

\section{E. Regional Influence Ability}

Regional influence ability generally refers that using a way easily accepted by others to change others' acceptable ways, change others' ideas and ability to act. Regional influence ability refers to the radiation of a certain region to the surrounding areas, and it specifically embodies in the economic development, social services, etc.

\section{F. Image Transmission Ability}

Image is the subjective impression of the transmitter in the people transmitted. Image transmission ability refers that the transmitter interacts with the people transmitted through the media, and let the disseminator to accept the transmitted object. The strength and weakness of image transmission capability have a direct impact on the dissemination results.

\section{THE COMPARISON OF CITY SOFT POWER AMONG SIX PROVINCIAL CAPITAL CITIES IN CENTRAL REGION}

Six central provincial capital cities respectively are Taiyuan in Shanxi, Zhengzhou in Henan, Hefei in Anhui, Nanchang in Jiangxi, Wuhan in Hubei, changsha in Hunan. In the aspect of city soft power, the six big cities have their own characteristics.

\section{A. From the Aspect of Cultural Attraction, All the Six central cities are Famous Historical and Cultural Cities}

Cultural attraction mainly manifests a kind of cultural power, and cultural power more performs in a city's cultural heritage. Culture heritage is highlighted from a city's building history, the total number of cultural resources, the total number of world cultural heritage, the number of cultural relics and its cultural circle and so on. Taiyuan is a civilization ancient city in North China with a long history of 2500 years, has a reputation of "dragon city". Zhengzhou is the hometown of the humanity ancestor Xuanyuan emperor, is one of China's eight ancient capitals, is one of the important birthplaces of Chinese civilization and Chinese culture, and is a famous historical and cultural city in china. Hefei was called Luzhou in ancient times, and it was always renowned for its "Cutting the throat right Huai, and the lip and teeth of Jiangnan", "The relics of three kingdoms, and the hometown of Bao Zheng" in the world. Nanchang is an ancient city of long history and culture, is the national historical and cultural city, is a revolutionary hero city, and has a name of world vibrant city. Wuhan city's abbreviation is Han and Chu, is one of birthplaces of Chu culture, is a national historical and cultural city, and is the cradle of modern Chinese industry. Famous Xin Hai revolution was firstly beginning here, and it has a reputation of Jiangcheng and nine provinces link Qu and the hometown yellow crane. Changsha is the birthplace of Chu culture and Xiang Chu culture, has experienced three thousand years of history, is the national historical and cultural city, national civilized city, is known as "star city", "Chu Han famous city”, and has profound Chu cultural connotation and Huxiang cultural connotation.

\section{B. From the Aspect of Social Cohesion, Nanchang, Wuhan and Changsha Stay in a Strength Status}

Social cohesion is an important part of the city comprehensive strength. In 2006 Taiyuan in Shanxi began to carry out environmental governance work, the implementation of the strategic restructuring, setting up "green high voltage line" in order to control the structural pollution, cut down the total discharge of pollutants, adjust the fuel structure, curb dust pollution. Zhengzhou's railroad, highway, aviation, subway traffic develop very well, the tertiary industry, service industry, exhibition industry suddenly rise as new forces, and social governance structure is well developed. Wuhan is rich in natural resources, and its traffic develops well. It has mild climate, its development is rapid, and great Wuhan construction is booming. Changsha develops its own cultural industry, animation industry, publishing industry, and the entertainment industry as a new force suddenly rises and has formed its own cultural brand using Huxiang culture advantage. Hefei is a famous higher education city, near the Yangtze River Delta, and as a rapid development in recent years. Its attraction is growing. Nanchang is a famous hero city, has a good revolutionary traditions, therefore its social atmosphere is good, and residents have high quality. Nanchang is the central city of central manufacturing industry, one of the national innovation cities, garden city, national civilization city and health city.

\section{From the Aspect of Educational Development Ability, Wuhan, Hefei and Changsha are more outstanding}

Education development ability is an important component of a city's soft power, perfect teaching system and rich teaching resources are important parts of the 
education development. Education development ability is compared mainly from universities, important laboratories and engineering technology center, national key discipline, post-doctoral research station, post-doctoral work station, doctoral discipline, master discipline, academician, the number of various types of professional and technical personnel, etc. Taiyuan, Zhengzhou, Nanchang, Hefei, Wuhan, and Changsha six cities are compared, in general, Wuhan's education strength ranks first, followed by Hefei, Changsha, Zhengzhou, Taiyuan, and the last one id Nanchang.

TABLE I. THE EDUCATIONAL DEVELOPMENT ABILITY COMPARISON AMONG SIX BIG CITIES

\begin{tabular}{|c|c|c|c|c|c|}
\hline City & Universities & $\begin{array}{c}\text { National Key } \\
\text { Discipline }\end{array}$ & $\begin{array}{c}\text { Doctoral } \\
\text { Discipline }\end{array}$ & $\begin{array}{c}\text { Master } \\
\text { Discipline }\end{array}$ & Academician \\
\hline Taiyuan & 36 & 22 & 100 & 404 & 18 \\
\hline Zhengzhou & 48 & 16 & 114 & 574 & 20 \\
\hline Hefei & 100 & 24 & 138 & 338 & 62 \\
\hline Nanchang & 56 & 12 & 83 & 226 & 36 \\
\hline Wuhan & 82 & 60 & 478 & 826 & \\
\hline Changsha & 55 & 44 & 136 & 376 & \\
\hline
\end{tabular}

D. From the Aspect of Science and Technology Innovation Ability, Central Six Cities have Their Respective Leading Strength in Different Areas

Innovation is the soul of a nation's progress, is an inexhaustible motive force for the prosperity of a country. Science and technology innovation includes the new discoveries of natural scientific knowledge and technological innovation two aspects. Science and technology innovation is the source for the development of social productive forces, and science and technology innovation ability plays a decisive role in economic and social development.

Taiyuan is a national important energy and heavy chemical industry city taking metallurgy, machinery, chemical engineering, coal as its pillar and taking output energy, raw materials and mining machinery products as the main feature. Zhengzhou has obvious advantages in textile, machinery, building materials, refractory materials, energy and raw material industry taking nonferrous metal, coal, food, tobacco and other industries as its main leading industry, and taking the automotive industry, advanced equipment manufacturing industry and the electronics information industry as Zhengzhou's three strategic support industry. Hefei is Chinese science and education city, and is the first pilot city in science and technology innovation in Anhui. It has a good innovation tradition and unique innovative ability, and has more than 200 various types of scientific research institutions. Nanchang is a higher education city, is the education base of national three largest occupations. Its universities and research institutes are more concentrated, science and technology have obvious advantages, and science and technology innovation ability is also higher. Nanchang national hi-tech industrial development zone is the most important research and development base in central China, and is the national five largest intelligence-intensive areas. Wuhan is our country's important educational center city, the level of higher education is ranked third in China, optical communications, biotechnology and life science, laser, microelectronic technology and composite technology, mechanical engineering, agricultural medicine, geology and geological resources and new materials and other areas stay in the national leading position. Changsha's science and technology strength is great, and its materials, machinery, metallurgy, medicine, transportation and bridge tunnel project are in a leading position in China.

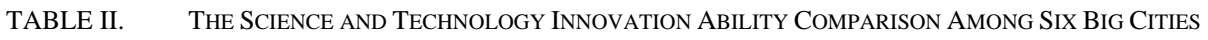

\begin{tabular}{|c|c|c|c|c|c|c|}
\hline City & $\begin{array}{c}\text { The Proportion of } \\
\text { Three Industries }\end{array}$ & $\begin{array}{c}\text { GDP Growth } \\
\text { Rate } \\
(\mathbf{2 0 1 0})\end{array}$ & $\begin{array}{c}\text { Energy } \\
\text { Consumption Per } \\
\text { Capita } \\
\text { (tee/人) }\end{array}$ & $\begin{array}{c}\text { Unit GDP } \\
\text { Energy } \\
\text { Consumption } \\
\text { (tee/km2) }\end{array}$ & $\begin{array}{c}\text { Provincial } \\
\text { R\&D Funds/ } \\
\text { (Billion } \\
\text { Yuan) }\end{array}$ & $\begin{array}{c}\text { Provincial R\&D } \\
\text { Funds Investment } \\
\text { Intensity (\%) }\end{array}$ \\
\hline Taiyuan & 0.50: 49.84: 49.66 & $11.0 \%$ & 6.10 & 1515.54 & 89.9 & 0.98 \\
\hline Zhengzhou & $0.85:$ 32.07: 67.08 & $13.0 \%$ & 5.65 & 1484.78 & 211.2 & 0.91 \\
\hline Hefei & $0.65: 48.67: 50.69$ & $17.5 \%$ & 3.56 & 688.71 & 163.7 & 1.32 \\
\hline Nanchang & $0.90: 49.83: 49.27$ & $14.0 \%$ & 3.52 & 814.34 & 87.2 & 0.92 \\
\hline Wuhan & $0.98: 45.95: 53.07$ & $14.7 \%$ & 4.82 & 907.54 & 264.1 & 1.65 \\
\hline Changsha & $1.03: 33.91: 65.06$ & $15.5 \%$ & 3.19 & 537.16 & 186.6 & 1.16 \\
\hline
\end{tabular}

Source: China's new city report in 2010, Written by Niu Wenyuan, Beijing, Science and Technology Press, 2010; 2010 National Science and technology funds statistical bulletin; The National Bureau of statistics; The Ministry of science and technology; The Ministry of finance. 


\section{E. From the Aspect of Regional Influence Ability, Central} Six Cities Have Formed Their Own Center City Circles

Regional influence ability mainly reflects from the city's economic development level and the radiation capacity to the surrounding areas. Taiyuan is the center of Shanxi provincial politics, economy, culture, education, science and technology, traffic, and information. In recent years, Taiyuan has developed into a modern industrial city taking metallurgy, machinery, chemical industry, coal industry as the main body, and its textile, electronics, food, pharmaceutical, electric power and building materials industry have owned a considerable scale, and industrial categories are relatively completed. Zhengzhou is a major city in the Midwest of China, is the large metropolitan and main economic center in central region, and has obvious advantages in the textile, machinery, building materials, refractory materials, energy and raw material industry taking nonferrous metal, coal, food, cigarettes and so on as its leading industries. In recent years, with the rapid development of modern service industry taking the information and finance as representatives, exhibition industry rises as a new force suddenly. Hefei is Anhui's largest city, is located between the Yangtze River and Huai River, and located in the side of Chao Lake. It links with other places via the South Fei River, and has an important location advantage linking East with West, and linking North with South. It is the political, economic, cultural, information, finance and trade center of Anhui province. Nanchang is the political, economic, cultural, science and technological, and transportation center of Jiangxi, is an important economic city in Yangtze River region, is one of three innovative manufacturing cities, is the central city of Poyang Lake's ecological economic zone, and is China's only one provincial capital city adjacent to the Yangtze River Delta, Pearl River Delta and Min delta. Wuhan is only one central vice provincial city, is central China's largest city, and especially is the big city of China's Yangtze River. Wuhan is an important industrial city and economic center of Yangtze middle and lower river region, is one of important cultural and educational centers, and is also an important transport hub in china. Changsha is located in the eastern Hunan Province, is located in the western margin of lower Xiang river basin, is the most competitive city of China's central and western regions, is an important central city in China, and is the especially big city in central south region. Changsha entertainment industry is developing rapidly, and is known as the entertainment capital of China.

TABLE III. The Regional Influence ABILITy Comparison AMONG Six Big Cities

\begin{tabular}{|c|c|c|c|c|c|}
\hline City & $\begin{array}{c}\text { Administrative } \\
\text { Region Soil Areas } \\
\text { (km2) }\end{array}$ & $\begin{array}{c}\text { Population } \\
\text { (million) }\end{array}$ & $\begin{array}{c}\text { GDP(million } \\
\text { Yuan) }\end{array}$ & $\begin{array}{c}\text { The Proportion of Three } \\
\text { Industries }\end{array}$ & $\begin{array}{c}\text { The Belonged City } \\
\text { Groups(Circles) }\end{array}$ \\
\hline Taiyuan & 1460 & 276.79 & 11146379 & $0.50:$ 49.84: 49.66 & Taiyuan City Cicle \\
\hline Zhengzhou & 1010 & 269.59 & 10254831 & $0.85:$ 32.07: 67.08 & Central China's City Group \\
\hline Hefei & 839 & 198.39 & 10244046 & $0.65: 48.67: 50.69$ & Wan River City Belt \\
\hline Nanchang & 617 & 224.25 & 9693371 & $0.90: 49.83: 49.27$ & Poyang Lake's City Group \\
\hline Wuhan & 2718 & 510.34 & 27090300 & $0.98: 45.95: 53.07$ & Wuhan City Circle \\
\hline Changsha & 556 & 218.75 & 12990284 & $1.03:$ 33.91: 65.06 & Chang-Zhu-Tan City Group \\
\hline
\end{tabular}

Source: China's new city report in 2010, Written by Niu Wenyuan, Beijing, Science and Technology Press, 2010 ; 2010 National Science and technology funds statistical bulletin; The National Bureau of statistics; The Ministry of science and technology; The Ministry of finance.

\section{F. From the Aspect of Image Transmission Ability, Central Six Cities Roughly Stay in the Same Level}

Image transmission ability is the important part of city soft power. Shanxi people have savvy and rugged characteristics of Jin businessman and the pioneering spirit of northern nomadic nationality. In recent years, Shanxi province and Taiyuan city actively promote the economic transition, improve resource utilization efficiency, and transform economic development mode solely depending on coal. The impression of outside world on Zhengzhou is the bold and aggressive characteristics owned by people in central plains. But in recent years, the people of Henan province are not popular by people in other provinces, even some employing units write a slogan that do not recruit people in Henan province in the process of recruitment. Zhengzhou in recent years continuously makes efforts to improve its image, ceaselessly improve people's living standard, and continuously perfect the infrastructure. Hefei people have Hui businessman's derivative, stable, sophisticated and delicate characteristics. Hefei gives people a new model city with rising momentum, and the credibility of the Hefei government continuously improves. Wuhan is the central important city, and it gives people a somewhat sly shrewd sense, "There is a bird with nine heads in heaven, and there are Hubei Yankees on earth" refers to the people in Wuhan city of Hubei province. In recent years, Wuhan city actively promotes big Wuhan construction, social economy gets rapid development, and becomes one of the pilot areas of resource saving and environment friendly society construction. Nanchang is a revolutionary hero city, has a reputation of world vibrant city, and is referred to the future metropolitan and green metropolitan. Under the influence of Huxiang culture, Changsha people do advocate a spirit that dare be the world first, and have a kind of spirit not easily admitting defeat. Under the traditional thinking of "emphasizing statecraft", Huxiang people are pragmatic and hard-working. It is the spirit that inspired Huxiang people continuously to pioneer and innovate generation by generation, and achieve to a peak of life and economic and social development. Changsha is a national innovation city, 
in recent years the infrastructure is ceaselessly perfect, and especially the tertiary industry develops rapidly.

\section{REFERENCES}

[1] Zhang Yong, Wang Shulin. Soft power and hard power: A new theoretical framework for Competitiveness Evaluation [J]. Hei Longjiang social science, 2009, (04):60-63.

[2] Jiang Mingsheng. Analysis on the moral appeal of grass-roots leading cadres [J]. Journal of Fujian Provincial Committee Party, 2008, (04):70-74.

[3] Liu Shaoquan. How to form leaders' cohesion in groups [J]. New world leader, 2010, (11):16-17.

[4] Lv Zhizhi. How to improve the credibility of the government [J]. Economic publication, 2011, (02):68-69.

[5] Peng Zhihong. Analysis on the countermeasure of improving the ability of science and technology innovation [J]. The science and technology of China's University, 2011, (21):47-48.

[6] Li Qingquan, Zheng Jifeng.The Establishing Target and Enhancing Path of Changsha-Zhuzhou-Xiangtan City Group's Soft Power [A].

[7] Zhu Konglai, Henry Zhang. Soft Power Innovation and Development in Today's China[C]. Sydney Australia: AUSSINO ACADEMIC PUBLISHING HOUSE, 2012. 418-423. 